$12-13-2013$

\title{
A Mightier Pin: Creating a Credible Reference Library on Pinterest at Murray State University
}

Rebecca Richardson

MurrayState University, rrichardson5@murraystate.edu

Candace Vance

Murray State University, cvance4@murraystate.edu

Elizabeth Price

James Madison University, price2el@jmu.edu

Jeffrey Henry

Murray State University, jhenry@murraystate.edu

Author(s) ORCID ID

Rebecca Richardson, http://orcid.org/0000-0002-9822-8315 Elizabeth Price, http://orcid.org/

0000-0002-7902-4202

Follow this and additional works at: https://digitalcommons.murraystate.edu/msufac_srct

Part of the Library and Information Science Commons

\section{Recommended Citation}

Richardson, Rebecca; Vance, Candace; Price, Elizabeth; and Henry, Jeffrey, "A Mightier Pin: Creating a Credible Reference Library on Pinterest at Murray State University" (2013). Faculty Research and Creative Activity. 1.

https://digitalcommons.murraystate.edu/msufac_srct/1 


\title{
A Mightier Pin: \\ Creating a Credible Reference Library on Pinterest at Murray State University
}

By

\author{
Rebecca Richardson, Candace Vance, Elizabeth Price, Jeffrey Henry \\ University Libraries, Murray State University, 2013
}

\begin{abstract}
This case study shows how the reference librarians at Murray State University use Pinterest as an added component in reference services. Statistics were collected in an attempt to monitor the number of items shared with the number of people who actively follow each board. This study will help interested reference librarians gain an understanding of how this social media site can be used to promote online resources, both those owned by the institution and those freely available on the internet. It will also serve as an example of how reference librarians can build a reference library within the confines of social media.
\end{abstract}

Keywords: Pinterest, social media, reference services, public outreach, community outreach, library 2.0, reference, digital library 


\section{Introduction}

The learner has evolved in recent years from those who seek knowledge from the physical books of Baby Boomers and Gen X to the increasingly visual world of the Millennials. This generation has never known life without computers and technology and these students are more visual and impatient in their learning styles. This is a world in which the World Wide Web has made it possible for people to access information a world away, from wherever they find an internet connection. Students at Murray State University are no different. They have access to the databases and research resources maintained behind proxy servers, but they are also becoming more visual and more social in their search methods. The Research \& Instruction (R\&I) Librarians at Murray State University (MSU) decided to attempt using the medium of social media, more specifically, Pinterest, to provide free reference / research resources to students and researchers.

\section{Background}

Murray State University, located in southwestern Kentucky, is a four-year public university with more than 10,800 students. The university's libraries serves traditional students, distance students, and the general community. Part of the vision of the MSU Libraries is to lead the campus in the advancement of technologies. One of the University Libraries' goals is to develop and promote physical and virtual spaces that adapt to the changing technological and learning needs of the university community (Murray State University Libraries, 2013). Social media has been adopted as an important component in engaging students and reaching out to the community in general. Social media is, "Forms of electronic communication through which users create online communities to share information, ideas, personal messages, and other content" 
(Merriam-Webster). In this case study it is the sharing of online reference resources within a community of users that fits this definition.

\section{Social Media and Pinterest}

Recent studies indicate that social media is an integral part of college students' lives in the United States. The Higher Education Research Institute (HERI, 2012) reported that 95 percent of high school seniors use social media. This is up from 86 percent in 2007, denoting growing integration of such forums into the lives of entering college students (HERI, 2012). And the younger generation is not alone in embracing these sites. The Pew Research Center found that 72 percent of online adults were using social networking tools in 2013 (Brenner and Smith, 2013). Today adult learners over the age of 25 make up 38 percent of undergraduate students in the United States (National Student Clearinghouse, 2012). University libraries around the world have been exploring ways to use social media to connect with students of all ages and the community. Murray State University Libraries have been on the forefront of this movement for several years, successfully employing Facebook, Twitter, and Instagram as additional avenues of communicating with users.

Image-based social media is growing quickly. Launched in March 2010, Pinterest was designed as a virtual pinboard for images. A social photo-sharing website, it allows users to collect images or videos on any topic. It began with personal users pinning recipes and craft ideas, but it quickly attracted businesses and educational institutions. Users can pin an image either found on the internet or from their own digital collection--and add written descriptions of up to 500 characters per pin. Some pins are simply images, but many pins are links to information about the image. Users can also 'repin' other users' pins or 'like' others' pins. As of 
April 2013, Pinterest users numbered 48.7 million, making it the fastest growing social media site in history (McBride, 2013). Unlike more common forms of social media, such as Facebook and Twitter, the content added to Pinterest pages does not get "lost" as more content is added. While items pinned to a Pinterest page are added at the top, they are still easily found and retrieved. In contrast, items posted to Facebook and Twitter begin at the top of the page and are moved down constantly as more content is added, making it difficult to find items posted days or weeks in the past.

Many libraries, both public and academic, have utilized Pinterest as another way to share their collections, programs and library events. Typically Pinterest is used to promote new books, special collections, children's books, image archives, reading lists, and/or library activities. MSU Libraries already had a main Pinterest page, promoting new materials within the library and other items of interest to the library community.

\section{Literature Review}

Myriad articles examining libraries' use of Web 2.0 tools, including social media (not distinguished from social networking sites for purposes of this review) have been published over the last five years, but few studies have targeted the effectiveness or return on investment for these tools. Gardois, Colombi, Grillo and Villanacci (2012) found that "no robust evidence of effectiveness emerges" from articles written about Web 2.0 services being implemented in academic, medical and research libraries. They coded 255 articles about Web 2.0 services aimed at different groups, including both students and faculty, students only, and the general public.The process or results of evaluations of these implementations were reported in only 122 (47.8\%) of the articles. Most of these evaluations used quantitative methods (83.6\%), either 
preliminary usage data over a short time or user satisfaction surveys. Assessments varied widely even among the same types of services. They suggested that "more rigorous research design and a clear evaluation strategy prior to implementation would be advisable."

Jacobson (2011) attempted to study perceived vs. actual use among libraries using strictly Facebook. She identified 12 libraries active on Facebook, with two libraries from six categories based on number of students (fewer than 3,000, 3,000-10,000 and more than 10,000) and type of library (branch campus, community college or special). She collected data on a single day and sorted the activity into five tiers that had been identified as potential uses for Facebook by Hendrix in a 2009 study: announcements/marketing/photos (Tier 1), reference services (Tier 2), forum for users (Tier 3), RSVP to events, OPAC search, Database search (Tier 4), and employee announcements and communication (Tier 5). The number of fans, wall messages, fan messages, photos, events, boxes, total updates, and days in existences were counted. She acknowledged the limitation of predicting or determining use for a social networking site since although libraries may create tools (such as discussion boards), that does not mean it will be "used" by fans. Jacobson found that the libraries were using Facebook "primarily as a marketing tool, and it may be valid to assert that this is currently the best use in the library realm." She concludes that librarians "may be more ambitious in our hopes for our Facebook presence than we can actually materialize."

Chu, Cheung, Hui, Chan \& Man (2010) surveyed academic librarians from universities around the world about the kinds of social networking tools the libraries were using, what the librarians thought about the use of those tools, and the advantages and disadvantages of social networking tools. Their response rate was low (27 library responses from 140 targeted participants), but among the 21 libraries using the tools, $73 \%$ agreed that the benefits of using 
social networking tools outweighed the costs, and $81 \%$ of the respondents indicated that the cost was minimal. The only cost identified by most respondents was staff time. Among the benefits were facilitating information sharing ( 7 of 21 ), promoting library services (10 of 21), facilitating knowledge sharing ( 3 of 21) and enhancing reference services (3 of 21).

Vucovich, Gordon, Mitchell and Ennis (2013) analyzed the use of Facebook, blogs, and YouTube to reach the varied user population of the Lister Hill Library of Health Sciences at the University of Alabama at Birmingham. Like Gardois et al, the authors found, "The usefulness of these tools has often proven elusive, and evaluating their impact is even harder to grasp in library settings," and suggested a more "fluid and dynamic way of assessing and evaluating the effectiveness of social media in a library setting is needed." With a lack of real data, they concluded the only way to determine whether the sites are worthwhile is to "experiment." Used Facebook since March 2008 to engage users and promote library resources and services, taking advantage of the Facebook Insights data to track likes, reach, engaged users and talking about this, and virality. Used Bitly URL shortener to create bookmarks that are shareable and tracks statistics of clicks. They found Facebook to be especially helpful for events and contests with prizes. In August 2012, LHL added a Pinterest account (10 boards with 218 pins and 66 followers). "The boards include pins to publicize events and resources at the library as well as images of possible interest." In early Fall 2012, reach of Facebook posts were smaller, causing them to speculate "the beginning of a shift away from Facebook for libraries that lack funding to pay for promoted posts." They concluded the social networking tools have been effective in reaching different user groups, and is an effective marketing tool for events and news based on the available metrics, making it a worthwhile investment in time. 
Romero (2011) discussed measuring the return on investment (ROI) of social media in the library, where ROI is simplified as the direct costs and revenues of each transaction. The growth of analytics services, such as those offered by Facebook and Google, has perpetuated the myth that the internet can be easily measured. In particular, ROI can be hard to quantify for notfor-profit institutions that are not quantifying transactions in terms of sales from links on social media sites. She did not offer suggestions on way to quantify these numbers for libraries. Still, she finds participation in social media "essential" for libraries. The tools of most interest to the library will be "those providing the library with a space for dialog, a space to talk about books and culture and to share information and documents."

Dunlap and Lowenthal (2009) examined using Twitter to "facilitate the process of social learning." Although this usage was restricted to professors and their classes, there are a few ideas that libraries can pull from their study. First, social networks help connect students with practicing professionals. Second, they support informal learning and allowed students to discover "resources and tools that they effectively applied to their coursework." Third, it allowed the faculty and students to develop ongoing relationships that weren't bound by the academic term. Among the disadvantages they noted, "Twitter can be time-consuming, addictive, and possibly even encourage bad grammar as the results of its 140-character limit." (citing Grosseck and Holotescu).

Grosseck (2009) analyzed the benefits of a variety of Web 2.0 tools in higher education, including social networking sites among those tools. Among the advantages she found were easier and faster access to information, a low level of complexity needed for use, and less time and energy spent during search and information management. Her disadvantages included the need for an interent connection, the vague significance of items offered for free, and a "second- 
hand web" as a medium for persons with low digital abilities. The R\&I librarians disagreed with these disadvantages, since social media can be a tool to reach out to these groups. Grosseck also felt that instructors needed to "interpret Web 2.0 technologies from a pedagogical perspective, so that students can become digitally fluent and ready for the challenges of a knowledge society." She found that the latest generation of Web 2.0 tools are "quickly becoming ubiquitous, offering many unique and powerful information, sharing and collaborating features."

In summary, social media and Web 2.0 tools can be useful tools for outreach and marketing, but it has been nearly impossible up to this point to quantify their effectiveness and ROI. The advantage of most social media tools is that accounts are free, so the only cost for implementing them is staff time. This leads many libraries to experiment with new tools, while still grappling with how to determine if the project is a success. To date, only two articles have been published specifically involving the relationship between Pinterest and academic libraries (Hansen, Nowlan, \& Winter, 2013; Thornton, 2012). Hansen et al. presented a case study on how Pinterest was used by the University of Regina Library in Canada. This study was the closest to what the R\&I Librarians at MSU Libraries were trying to accomplish. Thornton (2012) spent her time researching whether Pinterest was being used by academic libraries. She ran into the same issue as the the MSU R\&I Librarians--there was little to no research reported on the use of Pinterest by academic libraries.

Several trade journals and magazines published articles with general information about using Pinterest in libraries. These articles included the perspectives of teacher librarians, academic library professionals, and bloggers. These articles are mostly introductions to Pinterest, and "how-to" types of articles; e.g., how to use Pinterest to increase the online presence of your library, collections, and programs, etc. (Clark, 2012; Dudenhoffer, 2012; Ferguson, 2012; 
McDermott, 2012; Wilkinson, 2013). In addition to the professional websites, librarians who are personal bloggers have explored Pinterest with both introductions to the site and copyright information (DeSantis, 2012; Kroski, 2012; Murphy, 2012; Sims, 2012b).

A search of the literature illustrates how libraries are embracing Pinterest. Some libraries choose to use it as a place to spur creative ideas and activities for their library (Clark, 2012). However, most of the examples tend to include the use of Pinterest to point patrons toward materials that the library owns (Clark, 2012; Dudenhoffer, 2012; Hansen et al., 2012). When looking more specifically at academic libraries, some are branching out and using Pinterest to promote and describe school events, plan renovations, and identify areas of the online collection that are in need of more materials (DeSantis, 2012). Other academic libraries are incorporating Pinterest into information literacy classes to create unique interactive assignments that are easily integrated into both traditional face-to-face class settings as well as online distance education classes (Dudenhoffer, 2012).

This is not to imply that using Pinterest in libraries does not present a new set of challenges. The use of Pinterest, as with other social media technologies, has sparked concerns about the legality of certain activities because of copyright (Carpenter, 2013; Mon, 2012; Sims; 2012a; Sims, 2012b). Some libraries have taken lengthy precautionary measures to deal with the copyright issues involved with the use of Pinterest (Hansen et al., 2012).

In reading the literature available, it became clear that one idea had not been tried. Creating a library of free, credible resources on the visual social media platform, Pinterest, had not yet been attempted or studied. This concept of the reference/resource library of free sources for our students and more widely to the general public became one of the founding goals for the project at the MSU Libraries. 


\section{The Project}

In November 2012, several R\&I Librarians at MSU expanded the original Pinterest page and created subject-specific Pinterest boards to construct a digital research library of free, credible resources for our local and distant students, as well as the global community. For the purposes of this study a "digital library" is an organized collection of non-print resources for research (both personal and educational) purposes as described in the Online Dictionary of Library and Information Science (Reitz). Unlike some traditional library resources, the items "pinned" by the subject R\&I Librarians can be used by both students and the general public from anywhere in the world. This study, known as the Pinterest Project, was undertaken with the idea of seeing whether it was feasible to build such a digital research library and whether there would be an acceptable return on investment for an academic library.

\section{Methodology / Implementation}

In putting together a methodology for this study, the R\&I Librarians realized that no real instrument existed to measure the return on investment for a research library in social media. In research reported in Hansen, et al. (2013) and Thornton (2012), both groups decided to look at the number of followers their Pinterest pages had, but neither study gave definitive steps for collecting data. Therefore, the R\&I Librarians created guidelines and a data collection tool for use with this project. These guidelines were established with the idea that they could be used by other libraries in the future to set up a similar study / project.

The R \& I Librarians began by making a list of goals, setting guidelines, and choosing the criteria on which to base the findings of the research study.

The questions asked at the beginning of the study were very basic: 
1. Is it possible to build a usable research library of free, credible resources in the world of social media, specifically Pinterest?

2. If such a library is built, will it be utilized?

With these questions in mind, the researchers developed a list of guidelines for building the research boards on the Pinterest website and a data collection tool to assess the response to the boards:

1. Each board is to be built and maintained by the subject librarian for that department, who has specialized knowledge on information regarding those topics.

2. R\&I Librarians will choose websites and resources that they consider to be credible -educational websites from other schools/universities, museums, professional organizations, news sites, journals, corporate entities, government agencies, etc.

3. R\&I Librarians will pin only items that are verified URLs.

4. R\&I Librarians will verify pinned URLs every month to be sure the links still are accurate and working correctly. This is to be done manually, as we do not have a link resolver.

5. R\&I Librarians will evaluate usage monthly by the number of followers added each month, the number of likes, and the number of repins.

The return on investment for this study would be evaluated by the number of pins on each individual board, the number of followers the library / boards have, the number of times someone "liked" a pin, and the number times an item was "repinned." For the purposes of this study the following definitions apply: a "pin" is the sharing of a URL; a "board" is a virtual bulletin board where Pinterest participants link websites of interest for their own use and to share with others; a "follower" is someone who has decided to receive notices of any new items posted 
to the Pinterest page; a "like" is when someone wants to keep track of a specific pin, and a "repin" is when someone posts a "pin" to their personal board.

Each R\&I Librarian identified the boards he or she needed for departmental majors and also individual course lines within a major. They then asked the Library Systems Coordinator to add specific "pin boards" to the for MSU Libraries' existing Pinterest page (Murray State Libraries) and to share each board with the specific subject librarian. These research boards were maintained by individual R\&I Librarians. However, several boards were designed to assist students with general topics such as Research Help, Google Resources, and Infographic Creation; these were built and maintained by all the R\&I Librarians.

At the beginning of the project there were 32 boards, including both the general interest library boards and the research boards built for this study. The boards were organized with the general interest library boards at the top of the page followed by the research boards arranged in alphabetical order. As the project continued, boards were added until the Murray State Libraries Pinterest page contained 47 boards.

To begin adding websites to the Pinterest research boards, R\&I Librarians first used the external links on their university library guides. These were websites the R\&I Librarians already knew to be credible for research on specific topics. After they exhausted those choices, they began to research other universities' subject guides for ideas. Traditional sources were also consulted, including Choice reviews, books on reference services, journal and magazine reviews, and government websites. They also incorporated recommendations from students and professors who used sites in coursework or class projects. R\&I Librarians also used items pinned to Pinterest by other users; however, as per the guidelines, pins could only be added to the research boards using verified URLs. In other words, they would pin only from the original 
source / website and not from another Pinterest user. There was no set number of websites that had to be added each month. It was agreed that pressuring the R\&I Librarians to add a set number of websites monthly could jeopardize the credibility of URLs used on the research boards by forcing R\&I Librarians to add websites they were unsure about.

Data was collected monthly, generally during the first week of the month. Initially data collection involved counting the number of pins on each individual board, the number of followers for each individual board, the number of times someone "liked" a pin, and the number of times someone "repinned" a URL.

\section{Limitations}

Limitations to this case study became apparent as the R\&I Librarians began gathering data. They found that many of the aspects of use were not measurable in Pinterest. Analytic programs for Pinterest currently only measure statistics for items that are proprietary to the group or organization who pins it. If a pin does not originate from the website owned by Pinterest account holder, analytics do not count link usage. Someone conducting research on Pinterest can see how often a pin is "liked" or "repinned" but not whether a pin is used. Another limitation discovered was there is no way to know or measure who is accessing the Pinterest page or the amount of time an individual spends there. There is no way to gather information on the search needs of the user or how they found the page. There is also no way to contact someone who follows a Pinterest page to survey for feedback.

It was following the discovery of limitations that the R\&I Librarians decided to alter what usage data they were gathering. Despite having some items "liked," they stopped gathering the "likes" and "repins" and collected only the number of individuals who followed the Murray State Libraries Pinterest page. Laura Solomon explained, "When it comes to social media, the 
problem with ROI is that it was never designed to measure human interactions...Quantitative measurements that can be tracked include the number of fans or followers." (p. 44, 2011). This was agreed upon by Schrecker (2013) who pointed out that "like" and "repins" were not an accurate reflection of use because a pin can be used successfully without either of those actions taking place. For comparison's sake, imagine a pin is similar to a book on the shelf. A user could find the book, skim through it, take some notes, and return it to the shelf without anyone knowing about it. For those reasons, the R\&I Librarians began to focus their data collection on the number of followers they were accumulating.

\section{Analysis of Data}

While this project was conducted as a case study, data was collected for internal purposes - to see whether the number of followers increased or decreased and attempting to see who those followers were. The data collection tool used was relatively basic. It entailed the R\&I Librarian going to the Pinterest website and opening each individual research board and entering the number of pins on each board and the number of followers into Excel spreadsheets. As boards were added to Pinterest, they were added to the existing spreadsheet with the months prior to its addition showing as 0 . (See Table 1$)$.

The number of followers increased steadily in all boards going from an average of 39 followers at the beginning of data collection in December 2012 to an average of 74 individuals in July 2013. While there were new followers to the boards between December 2012 and January 2013, it was not enough to alter the average from 39. However, a definite increase was seen in January, going from an average of 39 followers to 50 . The researchers attributed this rise to the addition of the Pinterest research boards to the library guides on the MSU Libraries website. The 
average has continued to increase to the current average number of 74 followers per individual research board. (See Table 2).

Over the collection period the number of individuals following the main Murray State Libraries Pinterest page more than doubled from 55 followers in December 2012 to 122 followers in July 2013. This number differs from the number of followers on individual research boards because members of Pinterest can choose to follow only boards that interest them rather than an entire page of boards. Typically the number of followers on the main page is indicative of the total number of people interacting with the main page. The followers are not anonymous, and in the case of this study can be broken down into the following broad categories: Men (16); Women (77); Institutions - Libraries and Universities (18); Cities (2); Publishing Companies (3); and Other (5).

\section{Problems}

\section{Copyright}

One of the first problems discussed was copyright. Questions about whether Pinterest violated copyright cropped up in early 2012, causing at least one user to delete her account (Sims, 2012b). A librarian and lawyer, Sims states that the biggest copyright consideration is that 'Pinterest makes copies of the images people 'pin.' ... But it does not necessarily follow that because copyright is an issue when you make copies, copyright obviously and clearly prohibits the making of those copies." Moreover, the Pinterest terms of service were not that different from those on other social sharing sites. Sims concluded that "fair use probably covers some pinning, and implied or explicit licenses cover some more."

Librarians at the University of Regina responded to these concerns by creating a sevenstep questionnaire to determine whether an image could be pinned to their library boards 
(Hansen, Nowlan, \& Winter, 2012). In a non-library setting, Falkenberg (2012) quoted intellectual property lawyer Itai Maytal in support of a fair use defense: "Pinterest requires users to include a caption for the photos they pin. When pinning an image, the site prompts users to "Describe your pin..." This makes the argument that they are expressing a view on the original work -- and thus are entitled to the fair use defense -- more persuasive."

Carpenter (2013) examined the four factors of fair use and came to a similar conclusion. "Essentially, in the Pinterest context, two of the four factors significantly favor fair use (including the most important factor), one factor probably weighs slightly against fair use, and one factor does not favor either side. Considering this balance, it can be logically concluded that a court should and would find that most Pinterest users are protected from copyright infringement liability by the statutory fair use defense."

Copyright owners can contact Pinterest's designated copyright agent to have infringing content removed (Copyright, 2013). The account holder who pinned the image is notified that the content has been deleted from the site.

Weighing the evidence, the R\&I Librarians decided that because the aim of our "digital library" was to create the social media equivalent of an annotated bibliography of credible websites, the Pinterest boards would fall under fair use. Therefore, they did not come up with any formal set of questions or test to use before choosing sites to pin. As of July 2013, none of the R\&I Librarians involved in the project has been notified of any copyright complaints.

\section{Pinning Sites Without Images}

The first few months of our trial, the R\&I Librarians ran into several sites they wanted to add to their boards but that did not have images. Since Pinterest does allow users to upload their 
own image and direct that image to any website, at first they attempted to create a generic image, for example, a "MSU History Resource" logo, and use that to pin desirable but image-free sites. But the plain logos decreased the visual appeal of the boards and discredited the valid sources they represented. Vaknin (2012) explained how to use any image related to the site to create the pin. So they began using either cropped screenshots or images with Creative Commons licenses instead.

Komando (2013) explains how to take a partial screenshot on both Macintosh and Windows machines (the latter running Vista and later). The R\&I Librarians also employed several of the sites below for images when needed, and attempted to give credit to the original source in the content description on each pin (Richardson, Vance, Price, \& Henry, 2013):

- Creative Commons: http://creativecommons.org/

- Google Images: http://images.google.com/

- MorgueFile: http://morguefile.com/

- Compfight: http://compfight.com/

- Wikimedia Commons: http://commons.wikimedia.org/wiki/Main_Page

- Open Photo.net: http://www.openphoto.net/

- Library of Congress: http://www.loc.gov/pictures/

- Flickr Commons: http://www.flickr.com/commons

- U.S. government (http://www.usa.gov/Topics/Graphics.shtml)

Analytics

In spring 2013, Pinterest announced a new analytics service that allows verified business accounts to see who is pinning and re-pinning from their own site, how many people have seen 
the pins and how many are clicking on content (Pinterest web analytics, 2013). This tool would be beneficial for libraries or organizations pinning materials from their own websites, but it was not an option for the R\&I Librarians in this project because they were pinning mostly from external URLs.

\section{Marketing}

The marketing for this project was minimal. It included word of mouth and adding the Pinterest research board as an external URL page on the corresponding subject library guide. There was no formal marketing campaign for the Pinterest research boards. An upcoming website redesign may allow them to feature Pinterest more prominently and advertise the resources available there.

\section{Conclusion}

The R\&I Librarians believe this case study demonstrates it is possible to build a digital library of credible research resources within the confines of social media, specifically Pinterest, and that this library of resources will be used. In the case of the MSU Libraries, the number of followers to the research pin boards steadily increased and continues to increase. The R\&I Librarians believe this will happen based on the steady growth of Pinterest and increased number of followers despite few pins added to certain research boards. The researchers also project the number of followers growing with the addition of a campus-wide marketing campaign to increase awareness of the social media presence of the MSU Libraries that is scheduled for Fall 2013. In the future, the R \& I Librarians intend to market the boards outside Murray State University, particularly to those who have the need to credible research resources such as home school families and high schools students. 
The researchers will continue the study with boards being maintained as with the earlier study to see how the marketing campaign affects the number of followers on the Murray State Libraries Pinterest board. The R\&I Librarians hope that with the increased analytics available from Pinterest and similar companies, it will become possible to see how often links that do not originate from the Murray State University website are being accessed.

More research should be conducted to show whether the study could be replicated by other libraries both within Pinterest and other forms of social media. As technology advances the limitations found in this case study could disappear, the ability to measure the number of pins used and the length of time a person spends looking at a pin most likely will become available. A study could also be conducted to show the use of the more unorthodox types of pin boards by a library as opposed to the more traditional boards currently being utilized by libraries.

\section{References}

Adult learners. (2012, Spring). National Student Clearinghouse. Retrieved September 6, 2013, from http://www.studentclearinghouse.info/snapshot/docs/SnapshotReport4_Adult_Learners.p $\underline{\text { df }}$

Brenner, J., \& Smith, A. (2013, August 5). 72\% of online adults are social networking site users. Pew Research Center's Internet \& American Life Project. Retrieved September 06, 2013, from http://www.pewinternet.org/Reports/2013/social-networking-sites.aspx

Carpenter, C. C. (2013). Copyright infringement and the second generation of social media: Why Pinterest users should be protected from copyright infringement by the fair use defense. Journal of Internet Law, 16(7), 1-21. 
Chu, S.K.W., Cheung, H.S.C., Hui, J.S.C., Chan, R.L.S. \& Man, K.S.Y. (2010, August). Social networking tools for academic libraries. Paper presented at The International Federation of Library Associations and Institutions 2010. Gothenburg, Sweden.

Clark, A. (2012). Pinterest for librarians. Library Media Connection, 31.

Copyright. (2013). Retrieved from http://about.pinterest.com/copyright/

DeSantis, N. (2012, 2013). Three ways college libraries are exploring Pinterest. Retrieved from http://chronicle.com/blogs/wiredcampus/3-ways-college-libraries-are-exploringpinterest $/ 36195$ ?sid=wc\&utm_source=wc\&utm_medium=en

Dudenhoffer, C. (2012). Pin it! College \& Research Libraries News, 73(6), 328-332.

Dunlap, J. C., \& Lowenthal, P. R. (2009). Tweeting the night away: Using Twitter to enhance social presence. Journal of Information Systems Education, 20(2), 129-135.

Falkenberg, K. (2012). A one word fix to Pinterest's legal problem. Forbes.com, 2-2.

Ferguson, C. (2012). Technology left behind — Pinning in the library. Against the Grain, 24(3), 83-85.

Gardois, P., Colombi, N., Grillo, G., \& Villanacci, M. C. (2012). Implementation of Web 2.0 services in academic, medical and research libraries: A scoping review. Health Information \& Libraries Journal, 29(2), 90-109.

Grosseck, G. (2009). To use or not to use web 2.0 in higher education?.Procedia-Social and Behavioral Sciences, 1(1), 478-482. 
Grosseck, G., \& Holotescu, C. (2008, April). Can we use Twitter for educational activities. In 4th international scientific conference, eLearning and software for education, Bucharest, Romania. Cited in Dunlap, J. C., \& Lowenthal, P. R. (2009). Tweeting the night away: Using Twitter to enhance social presence. Journal of Information Systems Education, 20(2), 129-135.

Hansen, K., Nowlan, G., \& Winter, C. (2012). Pinterest as a tool: Applications in academic libraries and higher education. Partnership: The Canadian Journal of Library \& Information Practice \& Research, 7(2), 1-11.

Jacobson, T. B. (2011). Facebook as a Library Tool: Perceived vs. Actual Use. College \& Research Libraries, 72(1), 79-90.

Higher Education Research Institute. (2012). The American Freshman: National Norms Fall 2011.

Komando, K. (2013, July 12, 2013). Five tricks every computer user needs to know. USA Today. Retrieved July 12, 2013, from http://www.usatoday.com/story/tech/columnist/komando/2013/07/12/computer-tricksmemory-card-photo/2499135/

Kroski, E. (2012, 2012, August 2). 25 libraries to follow on Pinterest. Retrieved from http://oedb.org/ilibrarian/25-libraries-to-follow-on-pinterest/

McBride, S. (2013, February 20). Start-up Pinterest wins new funding, \$2.5 billion valuation. Retrieved from Reuters website: http://www.reuters.com/article/2013/02/21/net-usfunding-pinterest-idUSBRE91K01R20130221 
McDermott, I. E. (2012). Pinterest for Libraries. Searcher, 20(4), 7-45.

Merriam-Webster. (n.d.). Social media. In Merriam-Webster.com. Retrieved September 6, 2013, from http://www.merriam-webster.com/dictionary/social\%20media

Mon, G. E. (2012, March 21, 2012). The copyright question: How to protect yourself on Pinterest. Retrieved from http://mashable.com/2012/03/21/pinterest-copyright-legal$\underline{\text { issues/ }}$

Murphy, J. (2012). Pinterest for academic libraries [10/28/2012]. Web Retrieved from http://joemurphylibraryfuture.com/pinterest-for-academic-libraries/

Murray State University Libraries. (2013). Mission, vision, and value statements. Retrieved from http://lib.murraystate.edu/mission.htm

Pinterest web analytics. (2013). Retrieved from http://business.pinterest.com/analytics/

Reitz, J. M. (n.d.). Digital library. In Online Dictionary of Library and Information Science. ABC-CLIO. Retrieved September 6, 2013, from http://www.abcclio.com/ODLIS/odlis_D.aspx\#digitallibrary

Richardson, R., Vance, C., Price, E., \&amp; Henry, J. (2013, 2013, May 16). A mightier pin: Creating a credible research library on Pinterest. Retrieved July 15, 2013, from http://prezi.com/qf9pq8rgs-ar/?utm_campaign=share\&utm_medium=copy\&rc=ex0share

Romero, N. (2011). ROI. Measuring the social media return on investment in a library. Bottom Line: Managing Library Finances, 24(2), 145-151. doi:10.1108/08880451111169223 
Schrecker, D. (2013). One picture is worth ... Innovative uses for Pinterest. Paper presented at the Association of College and Research Libraries 2013 Conference, Speech presented at in Indiana Convention Center, Indianapolis.

Sims, N. (2012a). A few clarifications on Pinterest/copyright/TOS worries. Retrieved from http://blog.lib.umn.edu/copyrightlibn/2012/03/a-few-clarifications-onpinteresttoscopyright.html

Sims, N. (2012b). Pinterest, copyright, and terms of service. Retrieved from http://blog.lib.umn.edu/copyrightlibn/2012/03/pinterest-copyright-and-terms-ofservice.html

Solomon, L. (2011). Doing social media so it matters: A librarian's guide. Chicago: American Library Association.

Thornton, E. (2012). Is your academic library pinning? Academic libraries and Pinterest. Journal of Web Librarianship, 6(3), 164-175. doi:10.1080/19322909.2012.702006

Vucovich, L. A., Gordon, V. S., Mitchell, N., \& Ennis, L. A. (2013). Is the time and effort worth it? One library's evaluation of using social networking tools for outreach. Medical Reference Services Quarterly, 32(1), 12-25. doi:10.1080/02763869.2013.749107

Vaknin, S. (2012). Seven essential tricks for Pinterest power users. Retrieved 11/05/2012, from http://howto.cnet.com/8301-11310_39-57406125-285/seven-essential-tricks-forpinterest-power-users/

Wilkinson, Z. (2013). Oh, how Pinteresting! An introduction to Pinterest. Library Hi Tech News, 30(1), 1-4. doi: 10.1108/07419051311320904 
